\title{
The Time Varying Effects of Permanent and Transitory Shocks to Real Output
}

\author{
John W. Keating* \\ Victor J. Valcarcel* \\ -Department of Economics, The University of Kansas, 334 Snow Hall, Lawrence, KS 66045 \\ "Department of Economics, Texas Tech University, 257 Holden Hall, Lubbock, TX 79409
}

August 21, 2011

\begin{abstract}
Annual changes in volatility of U.S. real output growth and inflation are documented in data from 1870 to 2009 using a time varying parameter VAR model. Both volatilities rise quickly with World War I and its aftermath, stay relatively high until the end of World War II and drop rapidly until the mid to late-1960s. This Postwar Moderation represents the largest decline in volatilities in our sample, much greater than the Great Moderation that began in the 1980s. Fluctuations in output growth volatility are primarily associated with permanent shocks to output while fluctuations in inflation volatility are primarily accounted for by temporary shocks to output. Conditioning on temporary shocks, inflation and output growth are positively correlated. This finding and the ensuing impulse responses are consistent with an aggregate demand interpretation for the temporary shocks. Our model suggests aggregate demand played a key role in the changes in inflation volatility. Conversely, the two variables are negatively correlated when conditioning on permanent shocks, suggesting that these disturbances are associated primarily with aggregate supply. Our results suggest that aggregate supply played an important role in output volatility fluctuations. Most of the impulse responses support an aggregate supply interpretation of permanent shocks. However, for the pre-World War I period, we find that at longer horizons a permanent increase in output is generally associated with an increase in the price level that is frequently statistically significant. This evidence suggests aggregate demand may have had a long-run positive effect on output during the pre-World War I period.
\end{abstract}

JEL Classification: E30, E31, E65

Keywords: The Great Moderation; stochastic volatility; permanent-transitory decompositions; Markov Chain Monte Carlo; structural vector autoregressions.

\footnotetext{
We thank Tim Cogley and Luca Gambetti for beneficial correspondence and the generous sharing of code and Frank Schorfheide and participants in sessions at the Midwest Econometrics Group Meeting and at the Western Economic Association Meeting for providing helpful comments. All standard disclaimers apply.

Tel: 1-785-864-2837 E-mail: jkeating@ku.edu

* Tel: 1-806-742-2466 x239 E-mail: vic.valcarcel@ttu.edu
} 


\section{Introduction}

Economists frequently analyze data with statistical models of permanent and transitory shocks. One reason is pragmatic - many statistical packages have built-in procedures for estimating such models. A more important reason is that these models may serve as a means for addressing interesting economic questions. Models of permanent and transitory shocks have been applied most frequently to issues about real output. A prime reason is the relative ease with which one can generate a structural model in which aggregate supply is the source of permanent movements in output. Consider an economy in which long-run aggregate supply is independent of the price level and aggregate demand is negatively related to the price level. ${ }^{1}$ If shocks to aggregate demand have no permanent effect on any long-run aggregate supply factors (e.g. labor, capital, or productivity), then all permanent movements in output must be attributable to aggregate supply. These assumptions can be used to motivate the Blanchard and Quah (1989) decomposition of output into permanent and transitory shocks. ${ }^{2}$ We use a variant of their model that replaces the unemployment rate with the inflation rate which permits an examination of how the price level responds to these shocks.

It is not uncommon for statistical models based on the Blanchard and Quah decomposition to obtain evidence consistent with the underlying structural assumptions. For example, Bordo (1993), Karras (1994), Bayoumi and Taylor (1995) found that permanent shocks behave like aggregate supply causing price and output to move in opposite directions, while the transitory shocks behave like aggregate demand causing price and output to move in the same

\footnotetext{
${ }_{1}$ Alternatively, the price level may be replaced by the inflation rate, as in a New Keynesian Model.

2 Additional assumptions are required for the statistical model to identify permanent shocks as aggregate supply and temporary shocks as aggregate demand. One typical assumption is that supply and demand shocks are uncorrelated, although Cover, Enders and Hueng (2006) provide an approach which circumvents that assumption. Another common assumption is that the dynamic responses to shocks are invertible. For a discussion of invertibility and how to check for it in the context of a particular economic model, see Fernández-Villaverde, Rubio-Ramírez, Sargent and Watson (2007).
} 
direction. Related findings are obtained by Gambetti et al. (2008) using sign restrictions in a time-varying VAR. ${ }^{3}$

However, some evidence contradicts the simple structural model. For example, in preWorld War I data samples, Keating and Nye (1998) find that a permanent increase in output is associated with an increase in the price level in eight of the 10 countries in their study. In five of these cases the positive effect is statistically significant. This finding suggests that aggregate demand shocks may have contributed to permanent output movements during that particular period. 4

There is also evidence that the effects of permanent and transitory shocks are subject to quantitative, if not qualitative, changes over time. For example, Bayoumi and Eichengreen (1994) find that during the Bretton Woods exchange rate regime this model's parameters are significantly different from the period that followed. This sort of evidence has typically come from VAR models estimated over a small number of subsamples, each of which is assumed to have stable parameters. In contrast, this paper allows parameters to potentially change at each point in time through the use of a time-varying parameter VAR model. Another advantage of our model is that it allows for possible stochastic volatility in the errors. It seems reasonable to allow shock variances to change, particularly when studying an economy over a long period of time. Most work based on the Blanchard and Quah (1989) decomposition has not allowed for each of these types of time variation.

\footnotetext{
${ }^{3}$ An important distinction is that their analysis only deals with modern U.S. business cycles whereas our investigation examines a longer perspective on economic activity. They consider quarterly data from 1960 to 2008 while we use annual data from 1870 to 2009. The use of annual data raises some issues - for example see Faust and Leeper (1997) on temporal aggregation along with other possible concerns with the use of long-run restrictions. However, with the fixed parameter version of our model, Keating and Nye (1998) find that their main conclusions with annual postwar data are also obtained when quarterly postwar data are used. This observation suggests this paper would likely obtain qualitatively similar results if quarterly data were available for the full sample. ${ }^{4}$ Keating (2010) shows that under plausible and fairly general assumptions about the structure, when the price level rises with a permanent increase in output it implies that a positive (negative) aggregate demand shock has a permanently positive (negative) effect on the level of output.
} 
Our approach has certain benefits compared with previous work on the responses of output and the price level to permanent and transitory output shocks. We allow the data to provide more information on the way parameters may evolve over time. Our framework requires no assumptions about the timing, frequency, or size of changes in impulse responses. This is potentially important given that previous research has found evidence that responses to shocks may not be constant through time. Our more general model encompasses previous models that have assumed stable parameters within certain periods. One particular interest is how the price level's response to a permanent shock may have varied over time. Previous work with fixed parameter VARs obtained qualitatively different responses using pre-World War I and post-World War II samples. Our approach allows us to consider the following questions: Are previous findings robust to an entire sub-period or are they driven by a few large outliers within a specific sub-period? Is the evidence that the price level sometimes increases following a permanent increase in output an artifact of using a fixed parameter model?

Another important advantage of using a time-varying parameter approach is that it allows us to estimate a model that combines data from periods in which the economy behaved quite differently. Previously, it was common for economists to estimate fixed parameter models using sample periods that excluded the period from the beginning of World War I until the end of World War II. This exclusion was based on a belief that the economy operated in fundamentally different ways during periods of global warfare or world-wide depression. Our time-varying parameter model allows us to include these unusual episodes in the estimation and formally address that issue. We find evidence that the period from 1914 to 1947 was very different from the period that came before or afterwards.

Overall, the time-varying parameter VAR model with stochastic volatility finds a great deal of evidence to support the structural interpretation of the shocks in our model. Permanent 
and transitory shocks to output tend to behave like aggregate supply and aggregate demand shocks, respectively. However, the price level sometimes responds positively to a permanent increase in output at longer horizons. This unusual response is found at all dates in the preWorld War I subsample and in a small part of the post-World War II period. This pre-World War I finding supports previous work that was based on fixed parameters and an arbitrary sample period. But, to our knowledge, we are the first to uncover this unusual positive price level response to a permanent output shock in post-World War II U.S. data. In contrast to previous empirical work with the Blanchard and Quah decomposition, these results suggest the introductory textbook macro model that motivates this decomposition may not be applicable to the U.S. over the entire postwar period.

One of the most important aspects of our empirical framework is that it allows us to study how volatilities of inflation and output growth may vary over time. This part of our investigation is motivated by the common wisdom that the Great Moderation was an unprecedented event. While, previous research has frequently avoided data from earlier periods, we are not the first to examine changes in volatility from a historical perspective. For example, Romer (1999) considers data on unemployment rates, industrial production, and GNP since 1886 to conclude that pre-WWI and post-WWII volatilities are similar-broken only by higher volatilities during the interwar period. ${ }^{5}$ More recently, Nason and Smith (2008) employ data on real per capita GDP and consumption, as well as the consumption deflator measure of inflation and a "synthetically constructed" measure of the interest rate 6 to estimate a microfounded CCAPM within a GMM framework. They estimate a fixed parameter model within

\footnotetext{
${ }^{5}$ Romer replicates an old index of U.S. industrial production from 1869 to 1914 and extends it to cover the period from 1947 to 1982. She then compares average volatilities across the two periods to show that the postwar reductions are more muted when looking at her replicated index than what the more standard FRB IP measures suggest.

${ }^{6}$ Their interest rate measure comes from splicing the 6-month commercial paper rate and the 6-month certificate of deposit on the secondary market, both from the Federal Reserve.
} 
four sub-periods by breaking their sample in 1915, 1945, and 1984. They show that, on average, the volatility in output growth and inflation decreased by $53 \%$ and $57 \%$ respectively in the 1945 1984 period and decreased by 58\% and 72\% respectively in the post-1984 period. ${ }^{7}$ Neither paper econometrically estimates the break dates but instead takes them as given. In contrast, we econometrically estimate the posterior volatilities of output growth and inflation over the whole sample. An important advantage of our approach is that we let the data speak for itself by remaining agnostic about dates that parameters change. Another advantage of our approach, relative to the more traditional fixed-parameter SVAR models, is that it allows us to determine if these moderations take place gradually or rapidly.

We find that during what we term the U.S. Postwar Moderation, a period from shortly after World War II until the mid-1960s, the volatilities of U.S. output growth and inflation fell by $61 \%$ and $79 \%$ respectively. In comparison, these volatilities fell by $22 \%$ and $55 \%$, respectively, in our estimates over the period from 1984 to 1991.8 Thus, we find that the reduction in volatilities during the Great Moderation is not nearly as great as the reduction in volatilities that happened after World War II. Furthermore, we find that both volatilities in the post-1960 period are smaller than volatilities in the pre-1914 period, on average roughly half the size. Evidence of other moderations and other periods of relatively low volatility for the U.S. provide a better understanding of the scale and the significance of the period that has come to be known as the Great Moderation. ${ }^{9}$

\footnotetext{
7 Their estimates of the reduction in volatilities of output growth and inflation for the Great Moderation period are substantially higher than reported by McConnell and Perez-Quirós (2000) and Stock and Watson (2002), among others.

${ }_{8}^{8}$ Our measures are close to the $33 \%$ and $50 \%$ reductions in the volatility of output growth and inflation that Stock and Watson (2002) report as evidence of the Great Moderation that took place in U.S. economic activity since 1984.

9 These volatility findings are consistent with Keating and Valcarcel (2011). They obtained pre-1930 data from Mitchell (2003), in contrast to the Balke and Gordon (1989) data used here. The advantage of that Mitchell data is that it goes back to the late $18^{\text {th }}$ century, which allows them to estimate over a much wider time span. The disadvantage is that Mitchell's data is subject to various limitations as noted by Romer (1989), Balke and Gordon (1989), and others. Results based on Romer's data are essentially the same as the results in this paper. And in on-going research, we find similar volatility findings from other countries which have uninterrupted annual time series of similar length.
} 
Since we find that the volatility reduction during the Great Moderation is not an isolated incident, it would be useful to discover if changes in volatility have any common causal patterns. Our model finds that the permanent output shocks account for most of the changes in the volatility of output growth while the transitory output shocks account for most of the changes in inflation volatility. All the evidence suggests temporary output shocks are primarily associated with aggregate demand. Most of the evidence supports the hypothesis that permanent output shocks are primarily associated with aggregate supply, with the primary exceptions being longer run price responses to permanent output shocks in a few sub-periods. Changes in output growth and inflation volatilities are driven largely by shocks that have fundamentally different effects on output. ${ }^{10}$

The paper is organized as follows. Section 2 constructs the time-varying parameter model, specifies the identification strategy, and describes the analysis of second moments. Section 3 discusses data issues and sources. Section 4 describes the results from the timevarying impulse responses. Section 5 examines how volatilities have changed over time. We conclude in Section 6 with a summary of our main findings and a brief discussion of potential structural explanations.

\section{The Model}

\subsection{The TVP-VAR Model with Stochastic Volatility}

This section describes our VAR with autoregressive coefficients and a shock covariance matrix that are both time varying. Our model is similar to those of Cogley and Sargent (2001, 2005), Primiceri (2005), and Galí and Gambetti (2009). Consider the following $l$-th order VAR process

\footnotetext{
${ }^{10}$ Keating and Valcarcel (2011) obtain this result using Mitchell (2003) data and argue that this result is at odds with the good luck hypothesis explanation for moderations.
} 


$$
\theta_{t}(\mathrm{~L}) \mathrm{x}_{t}=e_{t}
$$

where $\mathrm{x}_{t}$ is an $\mathrm{n}$-vector of endogenous variables determined at time $\mathrm{t}$, each $\theta_{j t}$ in

$\theta_{t}(\mathrm{~L})=\mathrm{I}-\theta_{1 t} L-\ldots-\theta_{l t} L^{l}$ is a matrix of time-varying coefficients, and $\mathrm{e}_{t}$ is an n-vector of meanzero VAR innovations with the time-varying covariance matrix $R_{t}$. The coefficients in (2.1) evolve according to ${ }^{11}$

$$
\theta_{t}=\theta_{t-1}+u_{t}
$$

where $\mathrm{u}_{t}$ is a Gaussian white noise process with zero mean and constant covariance matrix $\mathrm{Q}$, independent of $\mathrm{e}_{t}$ at all leads and lags. ${ }^{12}$ Note that if $\mathrm{u}_{t}=0$ for all $\mathrm{t}$, our model reduces to a VAR with fixed coefficients and stochastic volatility. For convenience we omit means from this exposition, but in the estimation we allow the means to be time-varying following a process analogous to the autoregressive parameters in (2.2). We follow a variant of the Jaquier et al. (1994) stochastic volatility framework by decomposing the covariance matrix of the reducedform VAR as follows:

$$
E\left(e_{t} e_{t}^{\prime}\right) \equiv R_{t}=F_{t} H_{t} F_{t}^{\prime} \text { with } F_{t}=\left(\begin{array}{cccc}
1 & 0 & \ldots & 0 \\
f_{2,1, t} & 1 & \ddots & \vdots \\
\vdots & \ddots & \ddots & 0 \\
f_{n, 1, t} & \ldots & f_{n, n-1, t} & 1
\end{array}\right) \text { and } H_{t}=\left(\begin{array}{cccc}
h_{1, t} & 0 & \ldots & 0 \\
0 & h_{2, t} & \ddots & \vdots \\
\vdots & \ddots & \ddots & 0 \\
0 & \ldots \ldots & 0 & h_{n, t}
\end{array}\right)
$$

Let $h_{t}$ be a vector containing the free diagonal elements of $H_{t}$ assumed to be independent univariate stochastic processes that evolve according to the following:

$$
\ln h_{t}=\ln h_{t-1}+\xi_{t}
$$

\footnotetext{
11 This is a parameterization of a more general law of motion $p\left(\theta_{t} \mid \theta_{t-1}, Q\right) \propto I\left(\theta_{t}\right) f\left(\theta_{t} \mid \theta_{t-1}, Q\right)$ for the posterior densities of the states where $I\left(\theta_{t}\right)$ is an indicator function that carries out the rejection sampling mechanism necessary to rule out explosive paths of $x$.

12 According to Primiceri (2005), this assumption is not necessary but it allows for more efficient computations.
} 
where $\xi_{t} \sim \operatorname{iid}(0, \Xi)$. This random walk specification allows us to focus on permanent shifts in the innovation variance - such as those that are emphasized on the U.S. economic stabilization literature (Cogley and Sargent 2005) - while reducing the dimensionality of the estimation procedure (Primiceri 2005.) $)^{13}$

We stack all the off-diagonal elements of $F_{t}^{-1}$ into a vector $\gamma_{t}$ and, following Primiceri (2005), we assume that this vector evolves according to the following drift-less random walk

$$
\gamma_{t}=\gamma_{t-1}+\zeta_{t}
$$

where $\zeta_{t} \sim \operatorname{iid}(0, \Psi)$. All innovations are assumed to be jointly normally distributed with the following assumptions on the covariance matrix of the system

$$
\operatorname{var}\left(\left[\begin{array}{l}
\varepsilon_{t} \\
u_{t} \\
\xi_{t} \\
\zeta_{t}
\end{array}\right]\right)=\left[\begin{array}{llll}
I & 0 & 0 & 0 \\
0 & Q & 0 & 0 \\
0 & 0 & \Xi & 0 \\
0 & 0 & 0 & \Psi
\end{array}\right]
$$

where $Q, \Xi$, and $\Psi$ are positive definite $2 \times 2$ matrices, $I$ is a $2 \times 2$ identity matrix, 0 is a $2 \times 2$ matrix

of zeros and $\varepsilon_{t}$ is the vector of structural shocks. None of the off-diagonal zero restrictions are required for estimation. ${ }^{14}$ However, allowing for an entirely unrestricted correlation structure among the different sources of uncertainty would negate any structural interpretation of the innovations.

Following Galí and Gambetti (2009), we assume that the innovations $\left(\boldsymbol{e}_{t}\right)$ of the reducedform system (2.1) are a time-varying transformation of the underlying structural shocks that satisfy $\boldsymbol{E}\left(\varepsilon_{t} \varepsilon_{t}^{\prime}\right)=\boldsymbol{I} \quad \forall \boldsymbol{t}$. Thus, we have the following

$$
e_{t}=\varphi_{t} \varepsilon_{t} \quad \forall t
$$

13 This presents an alternative to ARCH models where the variances are generated by an unobserved components (UC) approach. 14 Primiceri (2005) outlines a minor modification to the estimation scheme to allow for non-zero off-diagonal blocks but cautions this comes at higher computational costs. 
where $\varphi_{t}$ is a nonsingular matrix that satisfies $\varphi_{t} \varphi_{t}^{\prime}=R_{t}$. Given this normalization scheme, changes in the contributions of different structural shocks to the volatility in innovations in the underlying variables of interest are captured by changes in $\varphi_{t} .{ }^{15}$

Let the companion form of (2.1) be given by

$$
\mathrm{X}_{t}=\Theta_{t} \mathrm{X}_{t-1}+D e_{t}
$$

where $\mathrm{X}_{t}=\left(x_{t}^{\prime}, x_{t-1}^{\prime}, \ldots, x_{t-\ell+1}^{\prime}\right)^{\prime}, \quad D=(I, 0, \ldots, 0)^{\prime}$, both of these matrices have the same dimensions, and $\Theta_{t}$ is the companion-form matrix derived from the autoregressive coefficients in (2.1). A standard local projection of (2.6) yields

$$
\frac{\partial x_{t+k}}{\partial e_{t}}=s_{2,2}\left(\Theta_{t}^{k}\right) \quad \forall t, \quad k=0,1,2, \ldots
$$

where $s_{2,2}(\bullet)$ is the appropriate selector function. ${ }^{16}$ Application of the chain rule yields the following impulse responses at an arbitrary $k$-th horizon

$$
\frac{\partial x_{t+k}}{\partial \varepsilon_{t}}=\frac{\partial x_{t+k}}{\partial e_{t}} \frac{\partial e_{t}}{\partial \varepsilon_{t}}=s_{2,2}\left(\Theta_{t}^{k}\right) \varphi_{t} \quad \forall t, \quad k=0,1,2, \ldots
$$

Our model is based on $y_{t}$, the logarithm of real output, and $p_{t}$, the logarithm of the price level, and both variables are first differenced: $x_{t}=\left(\Delta y_{t} \Delta p_{t}\right)^{\prime}$. For some purposes, we are interested in the effects on $p$ and $y$. That requires the use of cumulative impulse responses. These are obtained as follows. First, we define $\bar{\Theta}_{t}^{k}=\sum_{j=0}^{k} \Theta_{t}^{j}$. The level response of each variable to each shock after $\mathrm{k}$ periods is the accumulated response of the differenced series from period zero to period $k$. Then, following equation (2.8), the accumulated responses are given by

\footnotetext{
15 This model is general enough to allow for feedback between disturbances in drift and the covariance of the system even under more restricted scenarios than what we pose here.

16 Technically, the selector function is given by $s_{2,2}\left(\Theta_{t}^{k}\right)=D^{\prime} \Theta_{t}^{k} D$ which selects the upper left 2-by-2 matrix from the larger matrix.
} 
$M_{t, k} \equiv \sum_{j=0}^{k} s_{2,2}\left(\Theta_{t}^{j}\right) \varphi_{t}$. From the properties of the selector function, we obtain $M_{t, k}=s_{2,2}\left(\bar{\Theta}_{t}^{k}\right) \varphi_{t}$.

Furthermore, letting $k \rightarrow \infty$ allows us to define $M_{t} \equiv s_{2,2}\left(\bar{\Theta}_{t}^{\infty}\right) \varphi_{t}$ as a time-varying matrix of long-run cumulative multipliers which measure the long-run effect of each shock on output and the price level.

The underlying structural shocks, $\varepsilon_{t}=\left(\varepsilon_{t}^{P} \varepsilon_{t}^{T}\right)^{\prime}$, are identified by the assumption that a transitory shock does not affect the output level in the long run. This implies that our matrix of cumulative long-run multipliers is lower triangular. Thus, from the definition of $M_{t}$

$$
M_{t} M_{t}^{\prime}=s_{2,2}\left(\bar{\Theta}_{t}^{\infty}\right) R_{t}\left[s_{2,2}\left(\bar{\Theta}_{t}^{\infty}\right)\right]^{\prime}
$$

$M_{t}$ is obtained as the Cholesky factor of the right-hand-side of (2.9). Given $M_{t}$, we can solve for $\varphi_{t}$ as a function of the parameters in the VAR and obtain the structural impulse responses of each shock occurring at time t:

$$
\frac{\partial x_{t+k}}{\partial \varepsilon_{t}}=s_{2,2}\left(\Theta_{t}^{k}\right)\left[s_{2,2}\left(\bar{\Theta}_{t}^{\infty}\right)\right]^{-1} M_{t} \quad \forall t, \quad k=0,1,2 \ldots
$$

With the exception of the long-run output response to a transitory output shock, every response of each variable to each disturbance may evolve over time. Finally, we cumulate the effects on the differenced variables to obtain the dynamic responses of each variable to each shock:

$$
\frac{\partial\left(y_{t+k}, p_{t+k}\right)^{\prime}}{\partial \varepsilon_{t}}=s_{2,2}\left(\bar{\Theta}_{t}^{k}\right)\left[s_{2,2}\left(\bar{\Theta}_{t}^{\infty}\right)\right]^{-1} M_{t} \quad \forall t, \quad k=0,1,2 \ldots
$$

Note that $M_{t}$ is calculated in essentially the same way as Blanchard and Quah (1989), except for two important differences: First, we allow for time variation in the coefficients and the covariance matrix of residuals. And secondly, inflation is used as the second variable in the model, in contrast to Blanchard and Quah (1989) who used the unemployment rate. 


\subsection{Time-Varying Second Moments}

Each variable in our model has a time-varying moving average representation that is driven by the two underlying "structural" disturbances, the permanent and transitory shocks to output. Letting $\mathrm{x}_{i t}$ represent each variable, recursive substitution of (2.6) yields the following time varying moving average representation:

$$
\mathrm{x}_{i t}=\mu_{t}^{i}+\sum_{k=0}^{\infty}\left[\tilde{N}_{t, k}\right]_{i, P} \varepsilon_{t-k}^{P}+\sum_{k=0}^{\infty}\left[\tilde{N}_{t, k}\right]_{i, T} \varepsilon_{t-k}^{T} \quad \text { for } i=\left\{\Delta y_{t}, \Delta p_{t}\right\}
$$

where $\tilde{N}_{t, k} \equiv s_{2,2}\left(\Theta_{t}^{k}\right) \varphi_{t}$ applies the selector function, $S_{2,2}$, to the matrix of autoregressive

coefficients $\Theta_{t}$ from the companion form of the VAR raised to the power k. From (2.11) we determine how the time-varying unconditional variance of $\mathrm{x}_{i t}$ is decomposed into the contribution from each shock:

$$
\operatorname{var}_{\mathrm{t}}\left(\mathrm{x}_{i t}\right)=\sum_{k=0}^{\infty}\left[s_{2,2}\left(\Theta_{t}^{k}\right) \varphi_{t}\right]_{i, P}^{2}+\sum_{k=0}^{\infty}\left[s_{2,2}\left(\Theta_{t}^{k}\right) \varphi_{t}\right]_{i, T}^{2} \quad \text { for } \mathrm{i}=\left(\Delta y_{t}, \Delta p_{t}\right)
$$

Similarly the time-t covariance of $\Delta y_{t}$ and $\Delta p_{t}$ conditional on each shock is given by

$$
\begin{aligned}
\operatorname{cov}_{\mathrm{t}}\left(\Delta y_{t}, \Delta p_{t}\right) & =\sum_{k=0}^{\infty}\left[s_{2,2}\left(\Theta_{t}^{k}\right) \varphi_{t}\right]_{\Delta y, P}\left[s_{2,2}\left(\Theta_{t}^{k}\right) \varphi_{t}\right]_{\Delta p, P} \\
& +\sum_{k=0}^{\infty}\left[s_{2,2}\left(\Theta_{t}^{k}\right) \varphi_{t}\right]_{\Delta y, T}\left[s_{2,2}\left(\Theta_{t}^{k}\right) \varphi_{t}\right]_{\Delta p, T}
\end{aligned}
$$

The first summation captures the covariance between output growth and inflation contingent on the permanent shock, and the second summation reflects the covariance conditional on the transitory shock. Time-varying unconditional and conditional correlations follow tractably from the previous two expressions. 


\section{The Data}

Annual measures of nominal and real gross national product for the U.S. were obtained from Balke and Gordon (1989) for the period from 1869 to 1929. These same measures from 1929 to 2009 were retrieved from the St. Louis Fed's Federal Reserve Database (FRED). Real output from Balke and Gordon are obtained using the fixed base year method and 1982 prices. Real output from FRED are the NIPA measures obtained by the chain-weighting method. Our real output growth measure comes from splicing the growth rates of these two series. That series is plotted in Figure 1. Similarly, we spliced growth rates of nominal output from these two sources. Output levels in nominal and real terms were calculated by chaining growth rates for each output series. Then, the price level was obtained from the ratio of nominal to real output. Annual inflation rates are calculated and plotted in Figure 2. Henceforth, all references to output pertain to the real measure of output.

The pre-1929 and post-1929 data differ in terms of quality and in method for computing output. Splicing rather different measures of variables could potentially be problematic in the context of a fixed parameter model. However, this splicing is of less concern for us because changes in data quality can be handled by changing shock variances and possibly also changes in the VAR coefficients. While this aspect of our data may call into question comparisons of different results drawn from periods covered by different series, this will not have an appreciable effect on our postwar findings. Also, note that we experimented with alternative data and obtained remarkably similar findings. ${ }^{17}$

\footnotetext{
${ }^{17}$ Mitchell's alternative data source made possible alternative dates for splicing. We also used Romer (1989) data from 1869 to 1929 in place of the series from Balke and Gordon. Nearly all findings in this paper are robust to these alternatives. The only finding in this paper that is not replicated with other sources of data is that when using Mitchell data, we never obtain a statistically significant positive price level effect from a permanent shock to output. The failure to find this effect to be significant may be attributable to the relatively inferior quality of Mitchell's series compared with data from Romer or from Balke and Gordon.
} 


\section{The Evolution of Responses to Permanent and Transitory Output Shocks}

Time-varying impulse responses are constructed according to equation (2.10) which assumes temporary output shocks have no long-run effect on the level of output. We present two different perspectives on impulse responses. Figures 3a through 3d provide 3-dimensional (magnitude, date, horizon) impulse responses of output and the price level to a one-standarddeviation impulse to each shock. While each response is estimated up to 20 years ahead for each year from 1884 and 2009, these responses appear to settle down well before 20 years. These pictures provide a popular way of viewing the qualitative changes over time in each response. An important limitation of these 3-D plots is that they cannot be used for statistical inference. If we tried to append confidence bounds to these figures, the plots would become unintelligible.

For another perspective, we slice each 3-D response at each horizon. This allows us to plot each response at each horizon separately. These provide a better view on any quantitative changes in a response. Also, these figures permit a visually appealing way of attaching a 95\% confidence interval at each point in time. Figures 4 through 7 present these responses. ${ }^{18} \mathrm{We}$ only report horizons up to 10 years post-shock because every response appears to be unchanging henceforth. We believe that inspection of these responses, along with the 3-D graphs, permits a fuller understanding of how each response has evolved.

Figures 3a and 4 show output's response to a permanent shock. This response is always positive. Output rises immediately following a permanent shock and then gradually continues to rise until it reaches its long-run response. Clearly, the magnitude of this response varies over time. The response of output to a permanent shock tends to increase from the late $19^{\text {th }}$ century

\footnotetext{
18 The thick solid lines are posterior median estimates. The dotted lines represent $95 \%$ confidence bounds that are obtained by standard bootstrap methods similar to those of Gali and Gambetti (2009) but for time, rather than horizon, responses. There are other methods to compute bounds in these models. For example, Clark and Davig (2011) estimate confidence intervals around horizon impulse responses from posterior credible sets and Cogley and Sargent (2005) report inter-quantile ranges around posterior median estimates of second moments.
} 
until World War I. This effect stays elevated until after World War II and then begins a rapid decline. Since the 1960s, this response is smaller than any earlier time in our sample.

Figure 4 shows that this response was largest during the Great Depression, but stayed relatively high throughout the period from World War I to World War II. Prior to the 1970s, the output response to a permanent shock is more subdued on impact and increases by as much as $40 \%$ after two or three years. There is also evidence of a second reduction in the magnitude of the response taking place in the mid-1980s. This reduction coincides with the Great Moderation, but is substantially smaller than the decline in responses that began near the end of World War II. While the effects of permanent shocks to output are substantially smaller in the post-World War II period, at the end of the sample the magnitude of this response is rising toward levels not reached since the early 1980s. At each date, the magnitude seems to have largely settled to its permanent level by the fifth year. We note that the $95 \%$ confidence bounds for the period that includes the Great Depression and World War II do not overlap with the confidence bounds in the post-1960 episode. The postwar reduction in this response appears both large and statistically significant.

Figures $3 \mathrm{c}$ and 5 indicate that the short-run response of output to a temporary shock has also experienced substantial variation over the sample. For example, in the interwar period these responses are almost three times larger than the peak postwar response. During the postwar period, the magnitude of this output response rises during the Great Inflation from the late 1960s to the early 1980s and declines during the Great Moderation. The output effect of the temporary shock essentially disappears within five years at each point in time.

Figure 5 shows that this response is largest in the early 1920s, shortly after World War I. There are also local peaks during the Great Depression and shortly after World War II. The rise in this effect during the late 1970s and early 1980s is much smaller than the increases found 
during the world wars and the Great Depression. The lowest levels are generally in the 1960s and since the 1990s. For those sub-periods, the short-horizon confidence bounds do not overlap the bounds for most of the period from World War I to World War II, suggesting that these recent low levels are significantly smaller. This output response also incurs a substantial moderation immediately after World War II and a smaller moderation in the mid-1980s.

Figures $3 b$ and 6 show the response of the price level to a permanent increase in output. This effect varies in magnitude over time in much the same way that output varies in response to this permanent shock. The initial price response is typically negative or close to zero and, overall, it tends to be negative at all points along the response. However, in some periods this price response turns positive at longer horizons.

Figure 6 shows that the largest responses of price to the permanent shock, in absolute value, occur with the end of World War I and its aftermath. Here the response is negative. Other notably large negative responses occur shortly after World War II and from the late 1970s to early 1980s. At all points in time, the initial response is negative or zero and is frequently small. However, at longer horizons, this response is sometimes positive. For example, from the fourth year and beyond this response is nearly always positive in the pre-World War I period. These responses can be statistically significant, particularly in the years around 1900. The responses in the late-1950s to early-1960s are also positive and sometimes nearly significant, although they are much smaller than the positive pre-World War I responses. Most of the other responses are negative. The pre-World War I findings are qualitatively similar to those of Keating and Nye (1998) who find increases in the prewar U.S. price level from a permanent shock to output. And, like ours, their estimate is not statistically significant on impact but is significant at longer horizons. But their estimates assume fixed-parameters over a specific sample period while ours permit general time variation in parameters and shock variances. 
Our findings indicate that positive price responses to permanent output shocks were common to the pre-World War I period and did not result from an unusual event at some point in the data. Also, our results show that this previous pre-World War I period finding did not result from selecting 1914 as some arbitrary cut-off point for the sample. However, our results are more informative. Rather than looking at an average effect, we can determine the magnitudes for every year within our sample. For example, the peak positive price response is estimated to occur in 1901 . The response turns substantially and significantly negative in the interwar period, with the trough occurring in 1922. The response remains negative thereafter but statistically indistinguishable from zero, except for the period from the late-1950s to the early-1960s when it is almost significant and positive and the period between the late 1970s and early 1980s when the effect is significantly negative.

Figures $3 \mathrm{~d}$ and 7 show that the price level rises following a shock that temporarily raises output. This response gradually increases to an even higher long-run position. The magnitude of the response exhibits a substantial decline in the postwar period reminiscent of the output response to a permanent shock. There is also a noticeable increase in this response starting in the late 1970s, and in the early-1980s this response begins to decline. Since the 1990s, the response has stayed near its lowest value in our sample.

Figure 7 shows that the price level response to a transitory shock exhibits peaks and low levels at roughly the same points in time as the initial response of output to a transitory shock. Of course, while this price response is persistent, the output response-by construction - is not. These price responses are always positive and typically much smaller on impact than at longer horizons, results that are consistent with theories in which prices gradually adjust to aggregate demand shocks. By year four, the positive response between the mid-1910s and late 1940s more than doubles the initial response. By year six, the magnitudes seem to settle down to their long- 
run levels. We find evidence of substantial reductions in the magnitude of the response generally concomitant with those of the output response to this shock (as well as for output's response to the permanent shock). Here again, the largest reduction in magnitude takes place following World War II. The rise in the price level response from the mid-1970s to early-1980s is followed by a noteworthy decline during the period known as the Great Moderation. This reduction in magnitude is substantial but pales in comparison to the decline that began shortly after World War II. The response is positive but, while significant, very small in the 1990s and early 2000s compared to other periods.

The time-varying character of the responses reported in this section provides a number of insights that would be averaged away by the more traditional use of fixed parameter models. These graphs illustrate how a dynamic response can vary, sometimes by a change in the immediate impact of a shock and sometimes by a change in persistence. Overall, a number of interesting relationships are highlighted by our study of these impulse responses. First, the dynamics of these responses to permanent and temporary shocks to output tend to behave like aggregate supply and aggregate demand shocks, respectively. The primary exceptions are a few periods with positive long-run price responses to permanent shocks. Second, the responses tend to be largest in magnitude during the period from World War I to World War II. Third, responses decline sharply in magnitude during the postwar period, and the smallest magnitudes are typically reached in that period. Fourth, responses rise in magnitude somewhat during the 1970s and stay high until the early-1980s, in most cases reaching post-1960 highs. But these local peaks are not anything like the all-time highs from earlier in that century. Fifth, at the end of our sample, the magnitude of output's response to both shocks is increasing. 


\section{Time-Varying Persistence of the Estimated Responses}

Equation (2.12) defines the time varying variances of inflation and output growth while (2.13) defines the time-varying unconditional covariance. From these relationships it is straightforward to compute the time-varying unconditional correlation. These equations can also be used to calculate standard errors or correlations, conditioned on either the permanent or transitory shocks. By examining the contribution made by each shock we are able to provide a more informative picture of the relationship between inflation and output growth.

Figure 8 contains the correlation of output growth and inflation conditioned on each shock along with the unconditional correlation. This unconditional correlation tends to be negative, except for a brief period around 1900 when it is essentially zero. But the absolute value of this correlation is always small, with an estimate typically between -0.2 and zero. Conditioning on the transitory shock (the dashed line), the correlation of output growth and inflation is always positive and greater than 0.3. It declines from about 0.5 early in the sample to a low point in the 1970s and then rises to 0.4 at the end of the sample. In contrast, contingent on the permanent shock, the correlation between output growth and inflation (the dotted line) is always negative. It exhibits substantially greater fluctuations over time than the transitory shock contingent correlation. The most negative correlation is roughly -0.9 , occurring for a period following each world war and from the mid-1970s to the early 1980s. These minimum values coincide with local peaks in inflation variability, as we show later. This correlation is at its least negative in the late 1800s and early 1900s. It also is substantially smaller in absolute value from the late 1950s to the early 1960s as well as in the 1990s.

When conditioning on permanent shocks, output growth and inflation are negatively correlated, suggesting that these shocks are primarily associated with aggregate supply. On the other hand, when conditioning on the temporary shocks, these variables are always positively 
correlated. This correlation suggests that temporary shocks are primarily associated with aggregate demand. These estimates are consistent with the structural interpretation Blanchard and Quah (1989) gave to their decomposition. Blanchard and Quah, however, did not permit the correlation between output growth and their other variable - the unemployment rate - to vary over time. While the correlations generally support the traditional structural interpretation of their model, we have seen a few periods in which the impulse responses to permanent shocks call an aggregate supply interpretation into question.

Time-varying standard deviations of output growth and inflation are plotted in Figure 9. The solid line shows the estimates of output growth volatility over the sample. This volatility tends to rise from the 19th century until the 1930s. From World War I until the end of World War II, output volatility is higher than at any other period in the sample. Subsequently, output volatility began to fall dramatically until the mid-1960s. Output volatility declined by $61 \%$ during this period that we call the Postwar Moderation. The largest annual decline was $8.4 \%$ and occurred between 1947 and 1948. Volatility stabilized for some time, and then in the early 1980s it began falling again. We estimate a $22 \%$ reduction in the volatility of output growth between 1984 and 1991. This most recent decline is known as the Great Moderation, but it pales in comparison to the Postwar Moderation. Our results coincide, at least in spirit, with those of Blanchard and Simon (2001) who, based on U.S. data since 1952, argue that there has been a "steady decline in output volatility interrupted in the 1970s and early 1980s, with a return to trend in the late 1980s and the 1990s." Our own estimates suggest that the postwar moderation is characterized by a steady decline starting in the 1940s. Our estimates of stability gains associated with the Great Moderation are also more gradual than what much of the literature 
suggests and more in line with the protracted picture of Blanchard and Simon. ${ }^{19}$ We show that output volatility has been rising over the last few years, approaching the early 1980s levels. This has been observed by others using different methods and has caused some to question whether the Great Moderation has ended (Clark 2009). However, this recent rise in output volatility has not cut into the gains made during the Postwar Moderation, at least not yet.

The dashed line in Figure 9 shows the evolution of inflation volatility over the sample. It starts out relatively low, and in the years prior to World War I inflation volatility achieves low levels not seen again until after World War II. ${ }^{20}$ This volatility increased somewhat during The Panic of 1907, and then rose particularly fast during World War I. It was somewhat lower during the interwar period, but did not approach the low levels of the late $19^{\text {th }}$ and early $20^{\text {th }}$ centuries. And during the worst years of the Great Depression when deflation was most severe, inflation volatility increased substantially. There is also a modest spike in inflation volatility a few years following World War II, but afterwards volatility falls more in percentage terms than at any other time in our sample. The steepest postwar decline in inflation volatility occurs shortly after the 1951 Accord between the Treasury and the Federal Reserve, which relieved the Fed from its obligation to peg the long-term nominal bond rate. By the mid-1960s inflation volatility had fallen by roughly $79 \%$ - with the largest annual decline of $20.5 \%$ occurring between 1953 and 1954. Then inflation volatility rises, slowly at first, but more rapidly by the mid-1970s. The local peak in the 1970s is roughly the same volatility of inflation as the preWorld War I trough. In the early 1980s, inflation volatility falls again, reaching its historic low in

\footnotetext{
${ }^{19}$ In their paper, they conclude that the volatility of output growth was roughly cut in half for the U.S. between 1960 and 2000 . We estimate a $51 \%$ reduction over the same period here.

${ }^{20}$ Using the longer sample afforded by Mitchell's (2003) data, Keating and Valcarcel (2011) find that throughout most of the 19th century, inflation volatility exhibited wide fluctuations and a relatively high average level. But starting in the early 1880s, inflation volatility fell dramatically, hitting a low just before the Panic of 1907. Volatilities of inflation in the pre-World War I period were lowest during the Classical Gold Standard period irrespective of our choice of historical series.
} 
the 1990s. Since then, it has stayed in a narrow range between the all-time low from the 1990s and the local trough it reached in the mid-1960s.

It has been suggested by Romer (1986) and others that the volatility reduction in output growth during the 1940 s could be due to measurement error. In a related paper, Romer (1989) constructs a new GNP series from relatively more accurate pre-1909 data on commodity output. She finds that the interwar period stands out as a time of "immoderation" flanked by periods of similar volatility in output growth. Balke and Gordon's (1989) series do not, however, yield this same finding. Our results are quantitatively robust whether we employ the Balke-Gordon or Romer data sets. We find that since 1960 volatilities are virtually always smaller than they were in the pre-World War I period. Allowing for time-variation of a general nature apparently has a significant effect on how volatilities compare across time.

Equation (2.12) allows us to decompose the variance of each variable at each period into the sum of the variances contingent on each shock. Figures 10 and 11 provide estimates of the time-varying volatilities of output growth and inflation, respectively, along with the contribution of permanent and transitory shocks in each case. These enable us to determine the relative importance of each shock in explaining volatilities of each variable and how these contributions evolve over the sample period. ${ }^{21}$ Figure 10 illustrates how changes in output volatility are closely associated with permanent shocks. On the other hand, Figure 11 shows that variation in inflation volatility is largely explained by the transitory shocks to output. Thus our impulse responses, except for a few sub-periods for the permanent shock, and our correlations suggest that aggregate demand shocks account for most of the fluctuation in inflation volatility and aggregate supply shocks account for most of the variation in output growth volatility.

${ }^{21}$ The solid lines in each graph correspond to the time-varying unconditional standard deviations that were reported in Figure 9. 


\section{Conclusions}

This paper documents changes in volatility of U.S. output growth and inflation and how these changes are related to permanent and transitory shocks to output. Both volatilities rise quickly with World War I and stay relatively high until the end of World War II. Then, they both drop rapidly until the mid to late-1960s. The volatility of output growth essentially levelsoff around 1970, while inflation volatility rises throughout the 1970s. But in the 1980s, both volatilities begin to drop during the well-known Great Moderation. By the end of our sample, output volatility is rising, approaching its level from just before the Great Moderation, ${ }^{22}$ while inflation volatility stays near its all-time low. Based on the recent increase in output volatility, there is some concern that the Great Moderation may have ended. However, there is no sign yet that the gains from the Postwar Moderation are in jeopardy.

The impulse responses of output to both shocks tend to be larger during periods when output volatility is high and smaller when this volatility is low. However, permanent shocks account for most of the variation in output volatility. Inflation and output growth are positively correlated, conditioning on the temporary shock, consistent with the aggregate demand shock interpretation. Impulse responses generally support this interpretation. These two variables are negatively correlated, conditionally on the permanent shocks, suggesting that these shocks are primarily associated with aggregate supply shocks. And while the responses are usually consistent with this structural interpretation, there are certain periods in which a permanent increase in output is associated with a permanent increase in the price level at longer horizons. This is not consistent with the standard interpretation of how aggregate supply shocks affect the economy. These unusual responses are a common feature in the pre-World War I period where

${ }^{22}$ Notice from Figure 4 that the response of output to a permanent shock is rising near the end of our sample, which suggests the recent increase in output volatility may persist. 
they are frequently significant. There is also a brief period in the postwar where this sort of response occurs; however, the magnitude is smaller and the estimates are not statistically significant - although some are nearly so. A plausible explanation for these unusual findings is that aggregate demand has at times had a long-run effect on output.

One of our interesting findings is the relatively large reduction in volatilities for output growth and inflation during the Postwar Moderation. Why did each of these volatilities undergo its most impressive reduction starting shortly after World War II? When trying to account for the Great Moderation, economists have focused on two general sources: policy reaction or structural change. And failing to find support for either of these, good luck (i.e. an exogenous reduction in shock variances) is another possibility. The more substantial Postwar Moderation may also be a consequence of these potential sources of moderation.

Policy changes that coincide with the beginning of the Postwar Moderation are clearly evident. For example, output growth volatility begins the most rapid descent shortly after passage of the Full Employment Act of 1946. Inflation volatility also begins to fall rapidly about that same time. This act states "Congress hereby declares that it is the continuing policy and responsibility of the Federal Government ... to promote maximum employment, production and purchasing power." (15 USC, §1021). The government's concern for achieving these objectives may have caused it to take actions that helped to stabilize fluctuations in output growth and inflation. ${ }^{23}$

Another policy change that occurred near the end of the war is the establishment of the Bretton Woods system that fixed the exchange rates of other countries to the dollar and tied the dollar to gold. The system was motivated by a belief that stable currencies would add stability

${ }^{23}$ Clarida, Gali, and Gertler (2000) argue that monetary policy was a major factor in the Great Moderation, while Sims and Zha (2006) find that the change in shock variances is most important. Stock and Watson (2002) find evidence that monetary policy plays some role, but one that is fairly modest. 
to the real economy and prices. Some believed Bretton Woods would return economies to a level of stability not seen since the Classical Gold Standard - the period from 1880 to 1913. Our estimates provide some support for this idea. Volatilities for inflation and output growth fell dramatically during the Bretton Woods regime, and both volatilities were smaller, frequently much smaller, during the Classical Gold Standard than at any other time before $1945 .{ }^{24}$

The scale of government spending may also affect volatility. Measured in terms of outlays as a share of output, government appears to be permanently larger after World War II compared to the period before World War I. Over the business cycle, government spending is less volatile than private spending. Hence, if government accounts for a larger share of the economy, it is quite possible the aggregate economy will become more stable. ${ }^{25}$

The role of government programs known as automatic stabilizers has also expanded in the postwar period. Automatic stabilizers respond endogenously to the state of the economy, requiring no modification to policies already in place. They serve to passively moderate income fluctuations. Income taxes are one example of an automatic stabilizer. Since World War II, taxes as a share of income in the U.S. have been persistently higher than they were in the pre-World War I period. Higher taxes can make after-tax income less volatile. That would tend to make consumer spending less volatile and consequently have a similar effect on aggregate output. ${ }^{26}$ Income support from unemployment benefits and Medicaid reduces output fluctuations for similar reasons. And both of these programs became increasingly important in the post-World War II period. Thus a greater role of automatic stabilizers in the postwar period may have contributed to the Postwar Moderation.

\footnotetext{
${ }^{24}$ While fixed exchange rate systems are associated with low and sometimes rapidly falling inflation volatility, our results indicate that fixed rates are not necessary for maintaining very low levels of volatility. The standard errors of both inflation and output growth have been at or near their historic lows over the last two decades, a time when the U.S. let its exchange rate float. ${ }^{25}$ See Andrés, Doménech, and Fatás (2008) for a recent look at some of the evidence and a DSGE model that can account for some of that evidence.

${ }^{26}$ Of course, higher tax rates may also have adverse consequences for economic growth.
} 
Alternatively, the Postwar Moderation may have resulted from structural change that is unrelated to government policies. Some attribute a good deal of the Great Moderation to innovations in inventory management. ${ }^{27}$ Whether or not inventories are an important contributor to the Postwar Moderation is an empirical question. Other changes in private spending might be even more important for the Postwar Moderation. For example, consumption accounts for about $70 \%$ of GDP in 2009, and consumer services account for roughly $47 \%$ of GDP. Both GDP shares have risen during the postwar period. Services have increased in part as a result of increased spending on healthcare and financial services. Since total consumption is less volatile than the rest of output and consumer services less volatile than total consumption, it is plausible that a rise in consumption - or its services component - as a share of GDP would make output less volatile. This mechanism may be an important factor, even after controlling for the effects of automatic stabilizers on consumption. ${ }^{28}$

In future research, we will apply the analysis in this paper to other countries for which time series of good quality are available over similar sample periods. That may allow us to determine if other countries have patterns of time variation in volatilities or in impulse responses that resemble the U.S. results or if there are systematic cross-country differences. A multi-country study may help economists understand what causes moderations. A fuller appreciation of the means by which countries achieve and maintain lower levels of volatility may lead to welfare-improving policies.

\footnotetext{
${ }_{27}$ See, McConnell and Perez-Quirós, (2000) and Davis and Kahn, (2008) for example.

${ }_{28}$ An interesting question is how much of a change in aggregate output volatility can be attributable to different spending components. While Blanchard and Simon (2001) made some progress on this issue, future research may develop new methods to better account for variations in volatility or the share of output for each spending component.
} 


\section{References}

Andrés, J.; Doménech, R.; Fatás, A. (2008) “The Stabilizing Role of Government Size” Journal of Economic Dynamics and Control 32: 571-593

Balke, N.; Gordon, R. (1989)"'The Estimation of Prewar Gross National Product: Methodology and New Evidence" Journal of Political Economy 97(1):38-92.

Bayoumi, T.; Eichengreen, B. (1994) "Macroeconomic Adjustment under Bretton Woods and the Post-Bretton Woods Float: An Impulse Response Analysis" The Economic Journal 104: 813-827.

Bayoumi, T.; Taylor, M.P. (1995) “Macroeconomic shocks, the ERM and Tri-Polarity" Review of Economics and Statistics 77: 321-331.

Blanchard, O.J.; Quah, D. (1989) “The Dynamic Effects of Aggregate Demand and Supply Disturbances" The American Economic Review 79(4):655-673.

Blanchard, O.J.; Simon, J. (2001) “The Long and Large Decline in U.S. Output Volatility” Brooking Papers on Economic Activity 2001-1:187-207.

Bordo, M.D. (1993) “The Gold Standard, Bretton Woods and Other Monetary Regimes: A Historical Appraisal," in M.T. Belongia ed. Dimensions of Monetary Policy: Essays in Honor of Anatol B. Balbach, Federal Reserve Bank of St. Louis, 123-191.

Clarida, R.; Galí, J.; Gertler, M. (2000) "Monetary Policy Rules and Macroeconomic Stability: Evidence and Some Theory" Quarterly Journal of Economics 115:147-180.

Clark, T.E. (2009) “Is the Great Moderation Over?: An Empirical Analysis" Economic Review, Federal Reserve Bank of Kansas City (4):5-42.

Clark, T.E.; Davig, T. (2011) “Decomposing the Declining Volatility of Long-Term Inflation Expectations" Journal of Economic Dynamics and Control, 35(7):981-999.

Cogley, T.; Sargent, T.J. (2001) “Evolving post World War II U.S. Inflation Dynamics” NBER Macroeconomics Annual 16:331-373.

Cogley, T.; Sargent, T.J. (2005) "Drifts and Volatilities: Monetary Policies and Outcomes in the Post WWII U.S." Review of Economic Dynamics 8:262-302.

Cover, J.P. Enders, W., Hueng, C.J. (2006) “Using the Aggregate Demand-Aggregate Supply Model to Identify Structural Demand-Side and Supply-Side Shocks: Results Using a Bivariate VAR" Journal of Money, Credit, and Banking 38, April,777-790

Davis, S.J.; Kahn, J.A. (2008) "Interpreting the Great Moderation: Changes in the Volatility of Economic Activity at the Macro and Micro Levels" Journal of Economic Perspectives 22(4):155-180. 
Enders, W.; Ma, J. (2011) "Sources of the Great Moderation: A Time Series Analysis of GDP Subsectors" Journal of Economic Dynamics and Control, 35:67-79.

Faust, J.; Leeper, E.M. (1997) “When Do Long-Run Identifying Restrictions Give Reliable Results?" Journal of Business \& Economic Statistics 15(3): 345-53.

Fernández-Villaverde, J.; Rubio-Ramírez, J.F.; Sargent, T.J.; Watson, M.W. (2007) “ABCs (and Ds) of Understanding VARs" American Economic Review 97(3):1021-1026.

Galí, J.; Gambetti, L. (2009) “On the Sources of the Great Moderation" American Economic Journal: Macroeconomics 1(1):26-57.

Gambetti, L. Pappa, E. Canova, F. (2008) “The Structural Dynamics of U.S. Output and Inflation: What Explains the Changes?" Journal of Money, Credit and Banking 40: 369-388

Jacquier, E.; Polson, N.G.; Rossi, P.E. (1994) "Bayesian Analysis of Stochastic Volatility Models" Journal of Business and Economic Statistics 12:371-389.

Justiniano, A.; Primiceri, G. (2008) “The Time-Varying Volatility of Macroeconomic Fluctuations" American Economic Review 98(3):604-41.

Karras, G. (1994) "Aggregate Demand and Supply Shocks in Europe: 1860-1987," The Journal of European Economic History 22:79-98.

Keating, J.W. (2010) “Interpreting Permanent and Transitory Shocks to Output When Aggregate Demand May Not Be Neutral in the Long Run" University of Kansas Working Paper

Keating, J.W.; Nye, J.V. (1998) "Permanent and Transitory Shocks in Real Output: Estimates from Nineteenth-Century and Postwar Economies" Journal of Money Credit and Banking 30(2): 231-251.

Keating, J.W.; Valcarcel, V. (2011) “Greater Moderations” Texas Tech University Working Papers

McConnell, M. M.; Perez-Quiros, G.P. (2000) “Output Fluctuations in the United States: What has changed since the Early 1980s? American Economic Review 90, 1464-1476.

Mitchell, B.R. (2003) International Historical Statistics: The Americas, 1750-2000 5th ed. Houndmills, Basingstoke, Hampshire ; New York : Palgrave Macmillan.

Nason, J.M.; Smith, G.W. (2008) "Great Moderation(s) and U.S. Interest Rates: Unconditional Evidence" The B.E. Journal of Macroeconomics 8(1) (Contributions), Article 30

Primiceri, G.E. (2005) “Time Varying Structural Vector Autoregressions and Monetary Policy" Review of Economic Studies 72(3), 821-852.

Romer, C.D. (1986) "Is the Stabilization of the Postwar Economy a Figment of the Data" American Economic Review 76:314-334. 
Romer, C.D. (1989) “The Prewar Business Cycle Reconsidered: New Estimates of Gross National Product, 1869-1908" Journal of Political Economy 97:1-37.

Romer, C.D. (1999) “Changes in Business Cycles: Evidence and Explanations” Journal of Economic Perspectives 13(2):23-44.

Sims, C.; Zha, T. (2006) “Were There Regime Switches in Monetary Policy?” American Economic Review 96(1), 54-81.

Stock, J.; Watson, M. (2002) "Has the Business Cycle Changed and Why?" NBER Macroeconomics Annual (Cambridge, Mass.: MIT Press) 159-218.

Summers, P. (2005) “What Caused the Great Moderation?: Some Cross Country Evidence" Economic Review, Federal Reserve Bank of Kansas City (3):5-32.

Taylor, J. (1993) “Discretion versus Policy Rules in Practice" Carnegie-Rochester Conference Series on Public Policy 39:195-214.

The Employment Act, Act of Feb. 20, 1946, ch. 33, section 2, 60 Stat. 23, 15 USC, $\$ 1021$

International Monetary Fund's International Financial Statistics collected through HAVER ANALYTICS 60 E 42nd St., Ste. 3310, New York, NY 10165-3310, United States (212)986-9300, (212)986-5857 fax, http:/ / www.haver.com 
Figure 1: U.S. Real GNP Growth 1870-2009 (source: Balke-Gordon and NIPA)

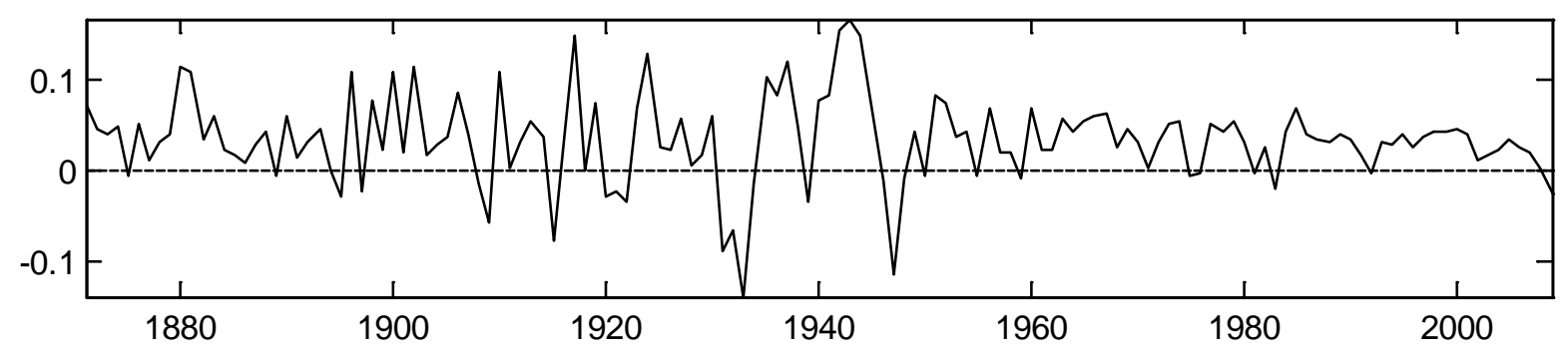

Figure 2: U.S. Inflation: 1870-2009 (source: Balke-Gordon and NIPA)

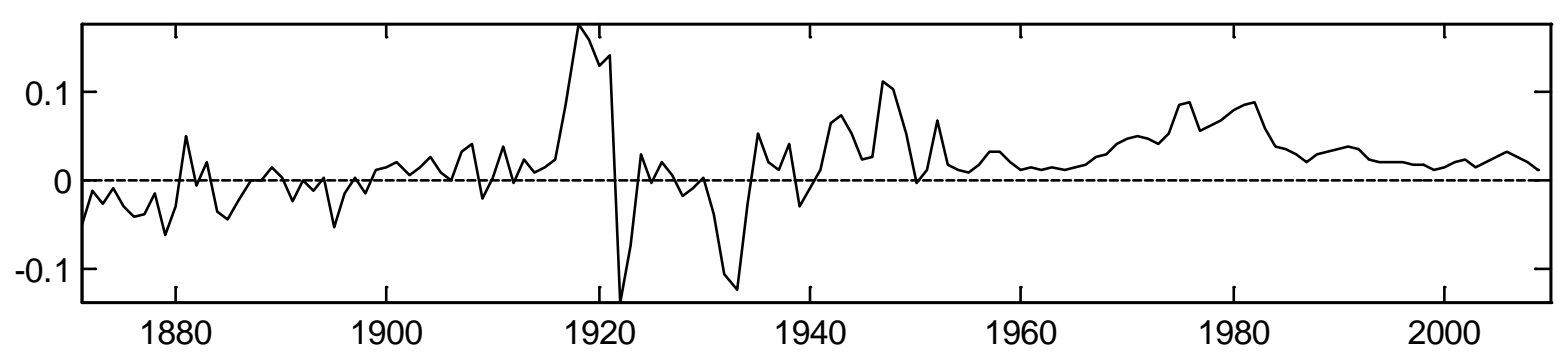


Figure 3: Time Varying IRFs: 1884-2009

(a)

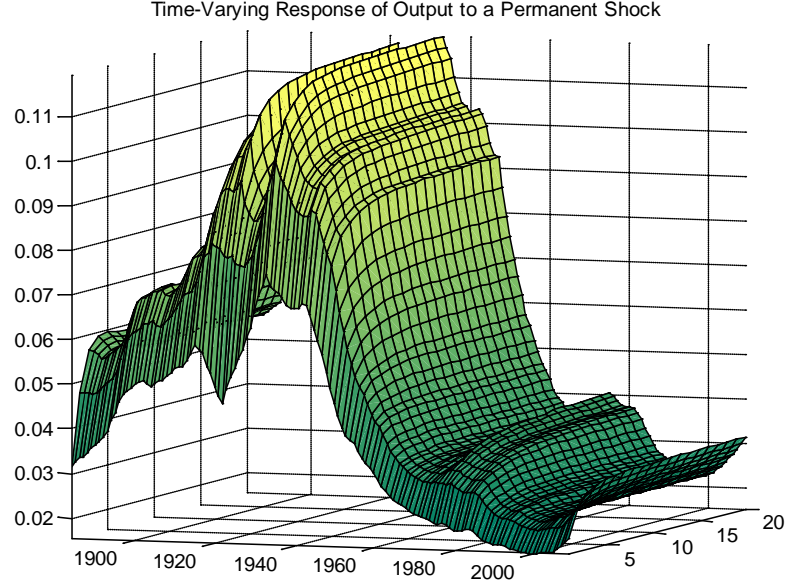

(c)

Time-Varying Response of Output to a Temporary Shock

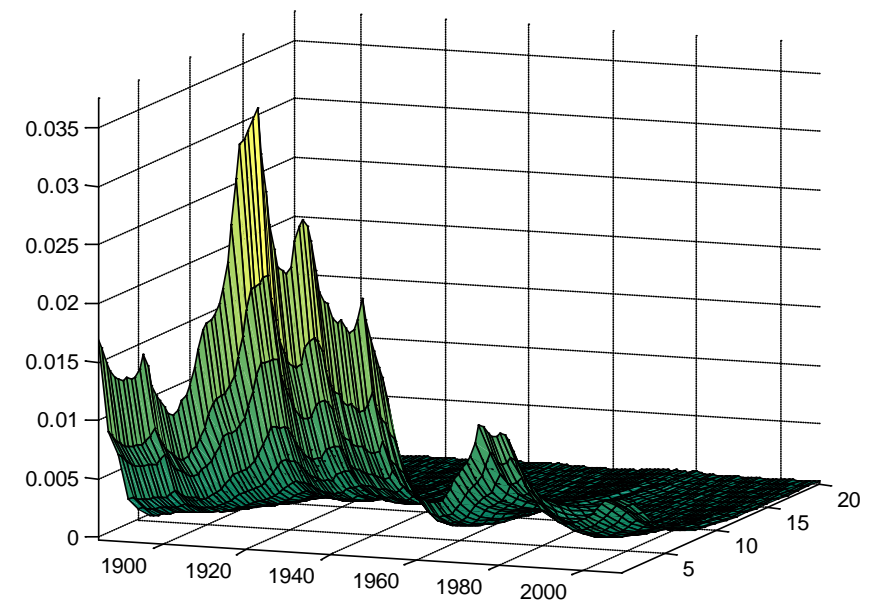

(b)

Time-Varying Response of the Price Level to a Permanent Shock

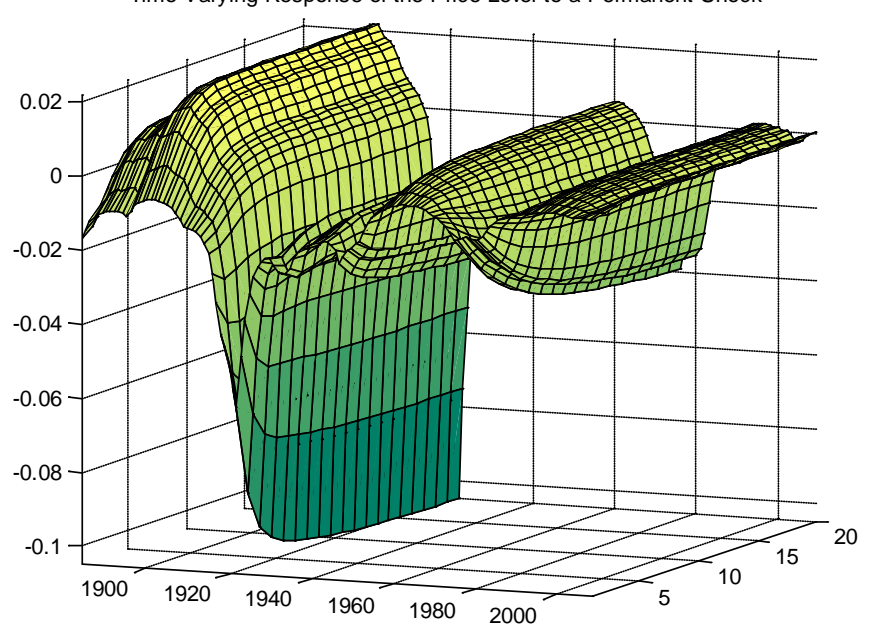

(d)

Time-Varying Response of the Price Level to a Temporary Shock

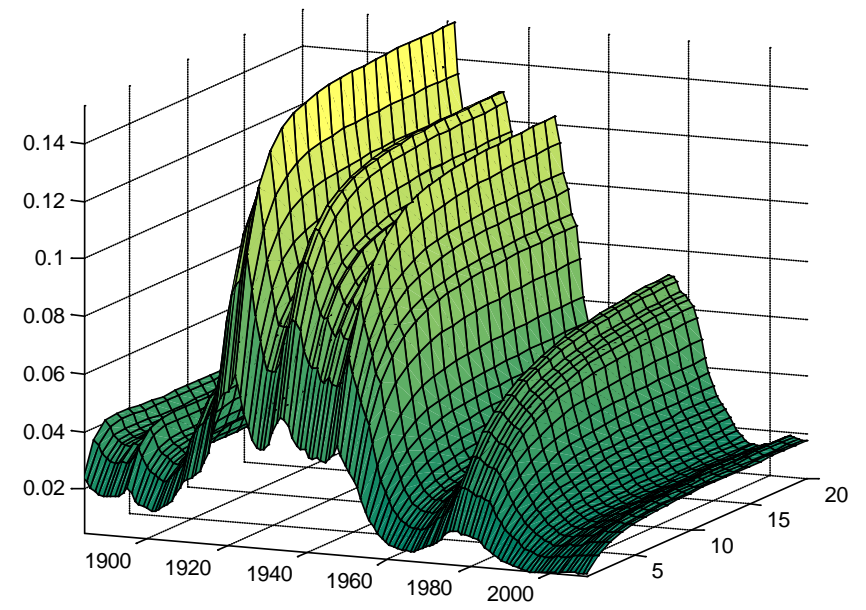


Figure 4: Output Response to a Permanent Shock at Various Horizons
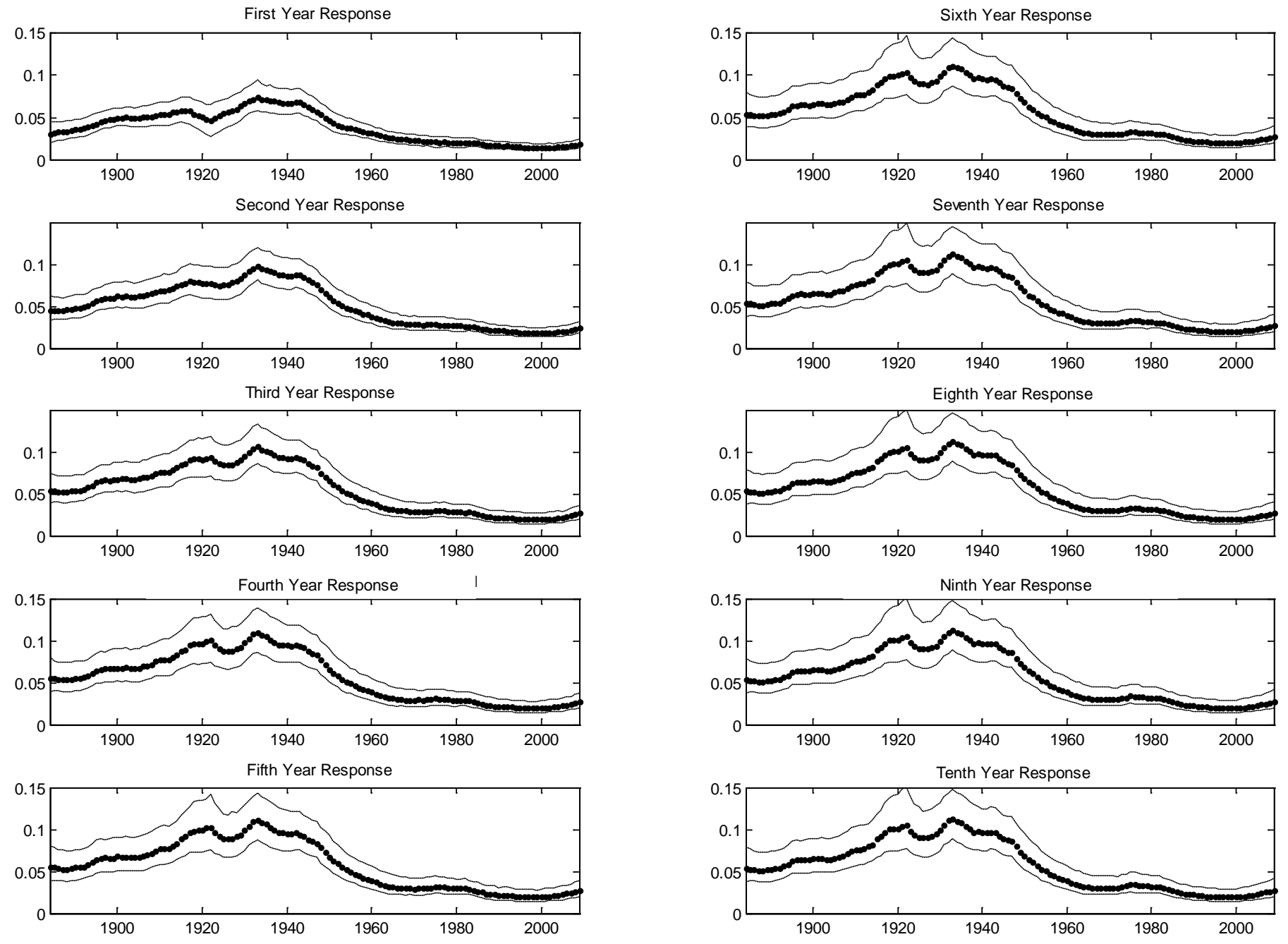
Figure 5: Output Response to a Transitory Shock at Various Horizons
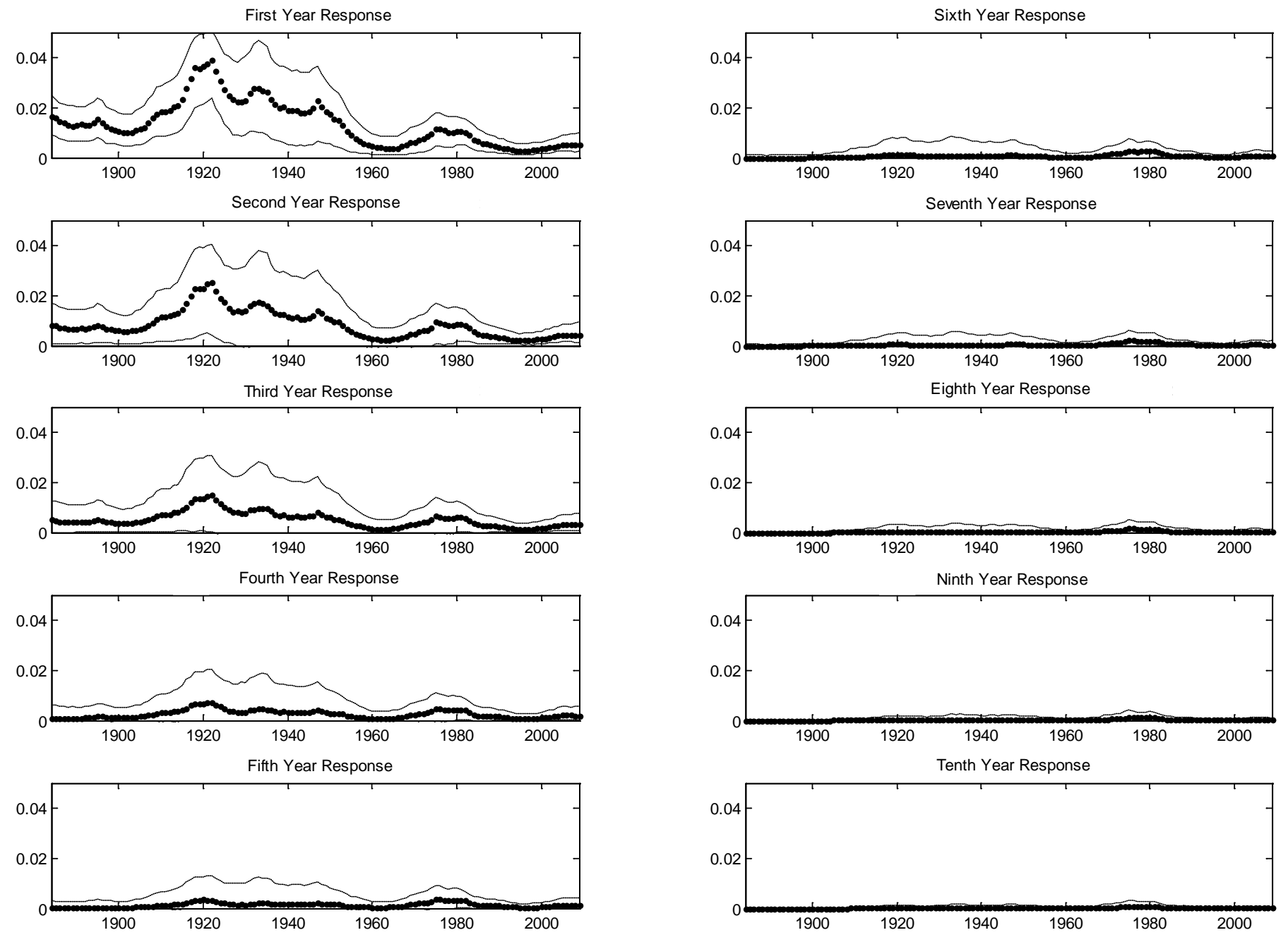
Figure 6: Price Level Response to a Permanent Shock at Various Horizons
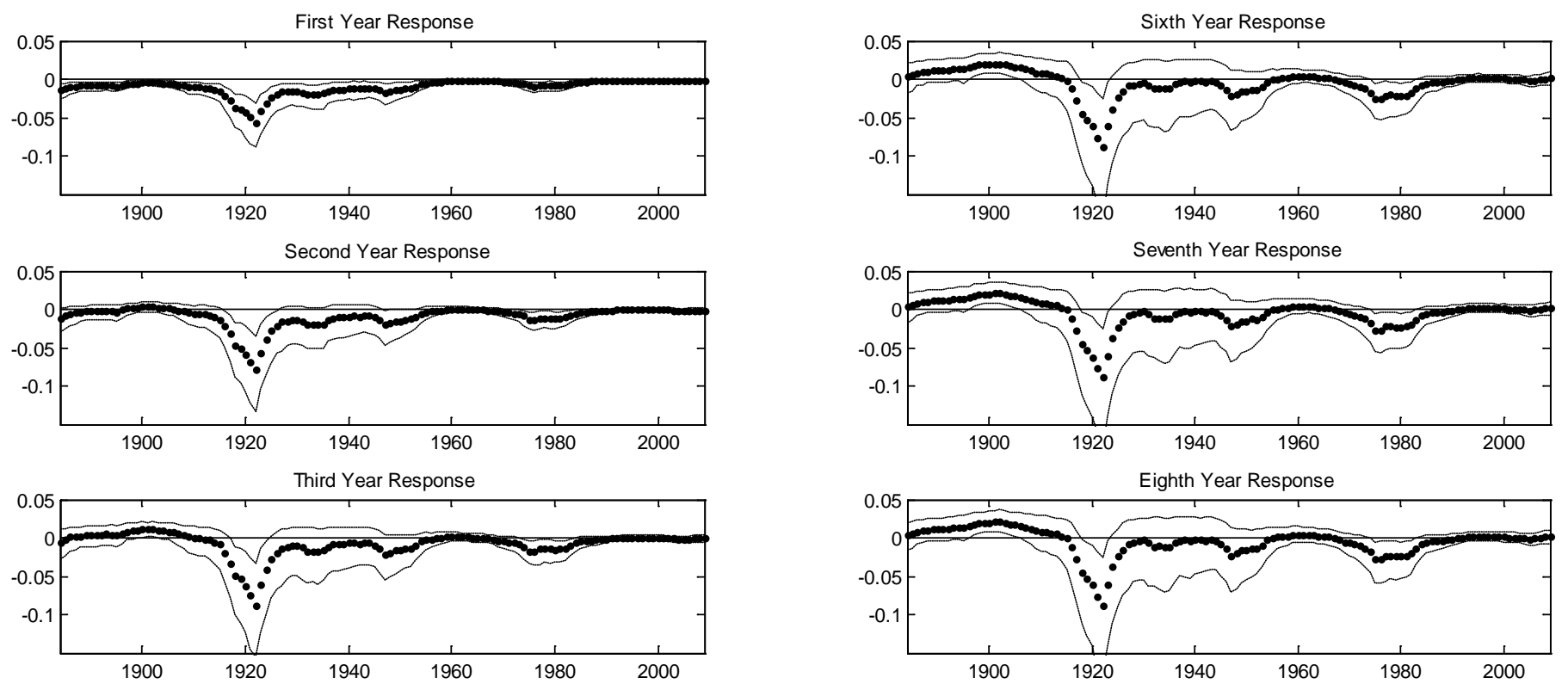

Fourth Year Response
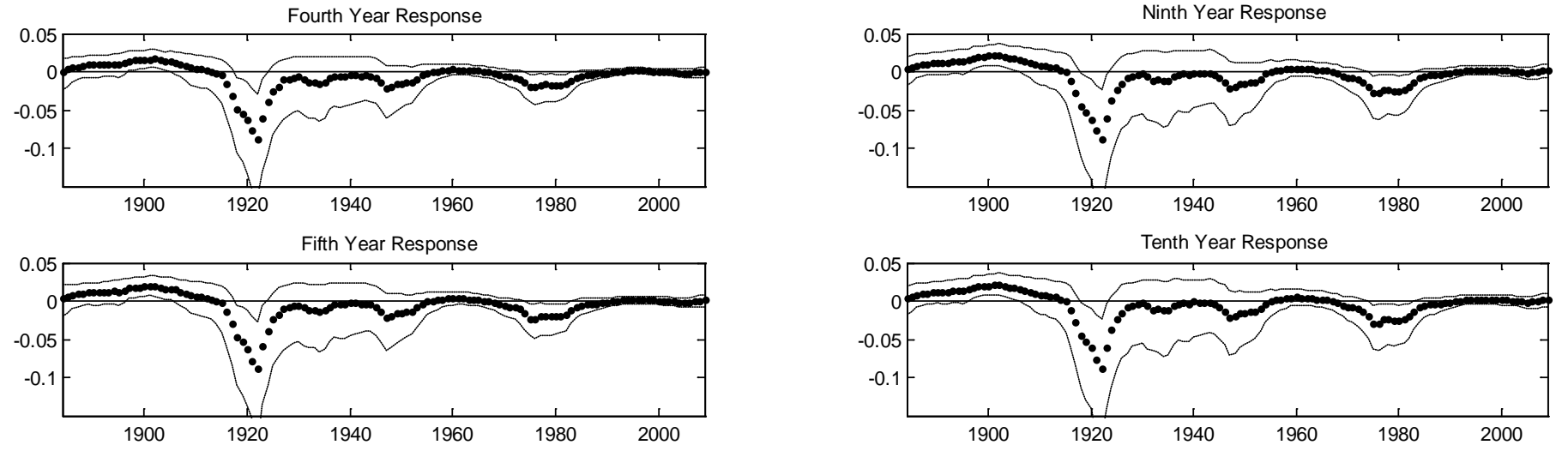
Figure 7: Price Level Response to a Transitory Shock at Various Horizons
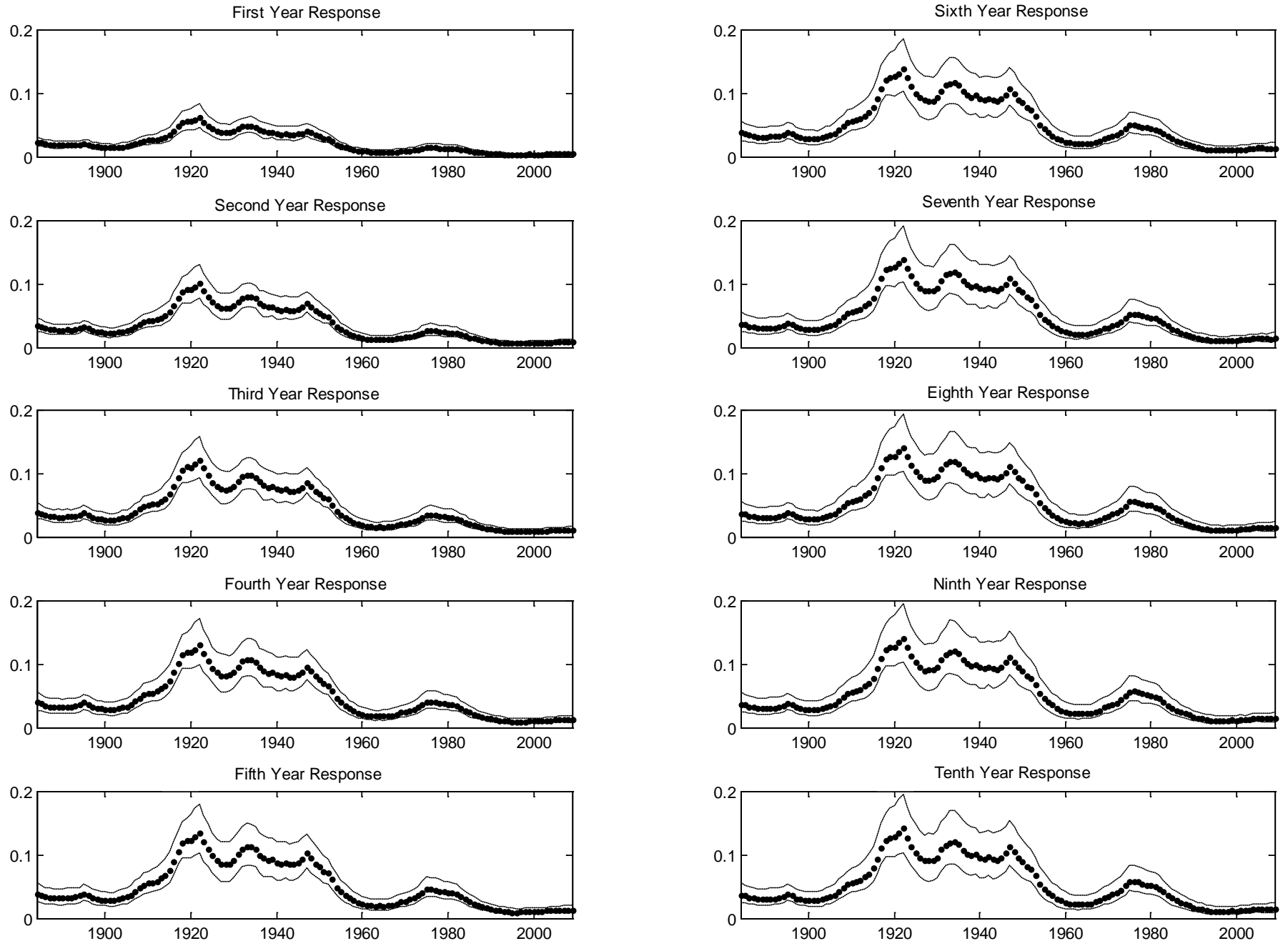
Figure 8: U.S. Real GNP Growth-Inflation Conditional Correlation

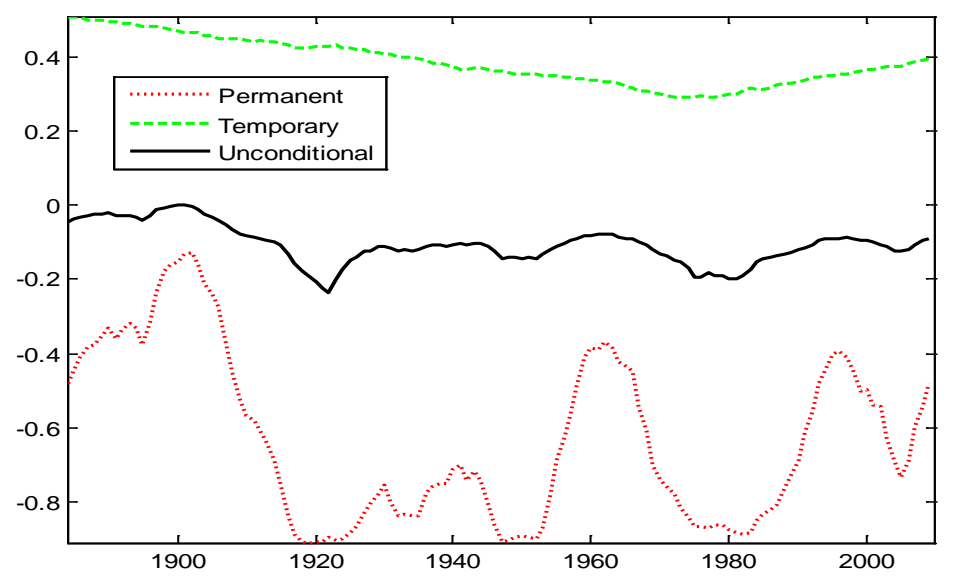

Figure 10: Conditional Standard Deviations for U.S. Real GNP Growth

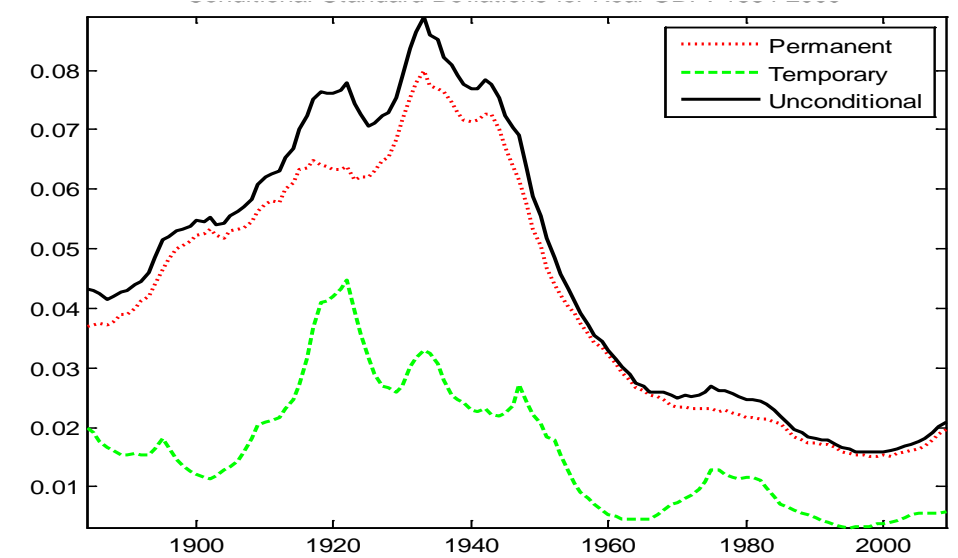

Figure 9: Time-Varying Standard Deviations

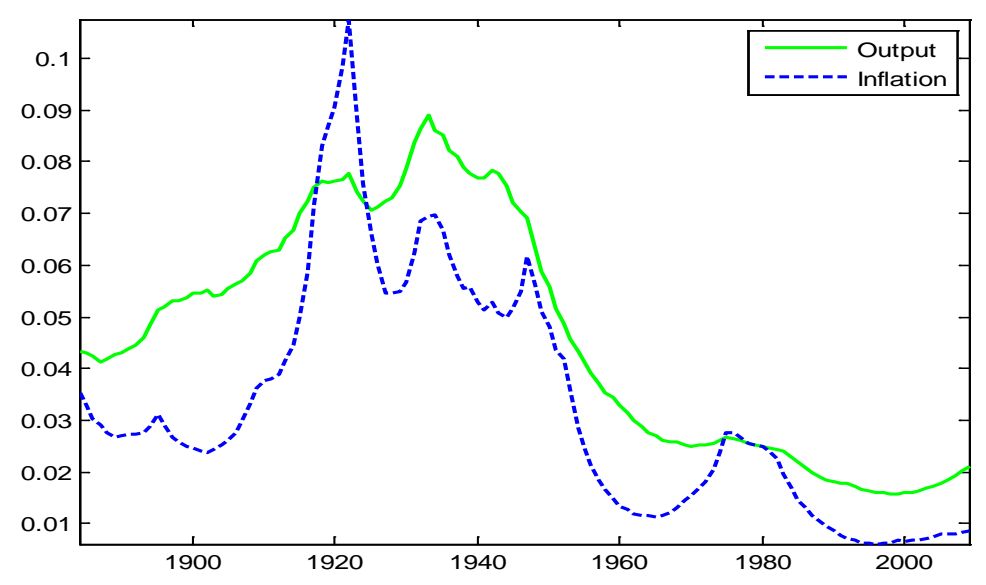

Figure 11: Conditional Standard Deviations for U.S. Inflation

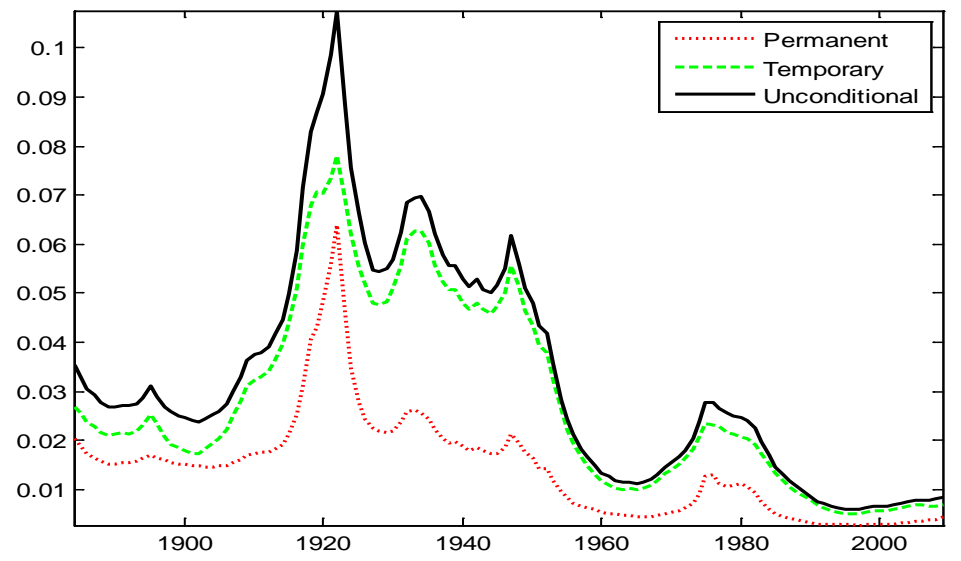




\section{Appendix}

This appendix describes the MCMC algorithm used to estimate the VAR with timevarying parameters and stochastic volatility. We estimate the model with a six-step Metropoliswithin-Gibbs MCMC algorithm, the construction of which follows methodology advanced by Jacquier et al. (1994) that many papers such as Cogley and Sargent (2005), Primiceri (2005), Gali and Gambetti (2009), and Clark and Davig (2011) have drawn applications from. The Gibbs sampler draws realizations from the posterior density iteratively. In our case, each iteration takes six steps to draw a subset of coefficients conditional on the data and realizations of the remaining coefficients and using these realizations in the conditional densities of the coefficients. The six steps draw time series for the following hyperparameters: the VAR coefficients $(\theta)$, the covariance matrix of the innovations to the VAR coefficients $(Q)$, the matrices for triangularizing the VAR residuals's covariance matrix $(F)$ and $(H)$ and the covariance matrices of innovations to that triangularization's coefficients $(\Psi)$ and $(\Xi)$, respectively. Under regularity conditions and after a burn-in period of 10,000 iterations, iterations on these six steps yield 20,000 draws from the joint density. We keep one of every 20 draws to break the possibility of serial correlation in the draws.

Step 1: $\operatorname{Draw} p(\theta \mid x, Q, F, H, \Psi, \Xi)$

The unrestricted posteriors of the VAR coefficients are normally distributed. Drawing them involves applying a standard Kalman filter to move forward in time and compute the conditional mean and variance of the terminal state $\theta_{T}$. For the posterior means and variances of all other states a backward smoother based on Carter and Kohn (1994) is used to draw 
coefficients from the posterior normal distribution. Following Primiceri (2005) we assume the that prior for the coefficients of the states is distributed according to:

$\theta_{0} \sim N\left\{\left(\hat{\theta}_{V A R}, V\left(\hat{\theta}_{V A R}\right)\right\}\right.$

where the zero subscript refers to the initial values, $\hat{\theta}_{V A R}$ is the vector of VAR estimates from a constant parameter VAR model estimated as an initialization with a training period up to 1884 , and $V\left(\hat{\theta}_{V A R}\right)$ is the estimate of the covariance over the same training sample.

Step 2: $\operatorname{Draw} p(Q \mid x, \theta, F, H, \Psi, \Xi)$

Following Cogley and Sargent (2005) and Primiceri (2005), the sampling of the covariance matrix of state equation is based on the following inverse Wishart conjugate prior $Q_{0} \sim I W\left\{\left[0.005 * V\left(\hat{\theta}_{V A R}\right)\right]^{-1}, T_{0}\right\}$ where $T_{0}$ refers to the initialization sample length. Step 3: $\operatorname{Draw} p(F \mid x, \theta, Q, H, \Psi, \Xi)$

Following Primiceri (2005) the observation equation can be rewritten as $F_{t} \tilde{x}_{t}=H_{t}^{0.5} \tilde{e}_{t}$ where $\tilde{e}_{t} \sim N(0, I)$ and where $\tilde{x}_{t}$ is observable conditional on $\theta$. We use Carter and Kohn algorithm to obtain a draw for $F_{t}$ by taking $F_{t} \tilde{x}_{t}=H_{t}^{0.5} \tilde{e}_{t}$ as the given observation equation and (2.4) in the body of the paper as the state equation. Since $\gamma_{t}$ and $\tilde{e}_{t}$ are assumed independent across equations, the algorithm can be applied equation by equation. In our bivariate case, the system simplifies to a single observable and a single state equations. The prior associated with this step is described as follows: $\gamma_{0} \sim N\left\{\left(\hat{\gamma}_{V A R},\left|\hat{\gamma}_{V A R}\right|\right\}\right.$ where $\hat{\gamma}_{V A R}$ is the initial estimate of the 2,1 element of the lower triangular matrix $F_{t}$. 
Step 4: $\operatorname{Draw} p(\Psi \mid x, \theta, Q, H, F, \Xi)$

Following Primiceri (2005) the covariance matrix of innovation to the 2,1 coefficients of $F_{t}$ is based on inverse Wishart conjugate priors

$\Psi \sim I W\left\{\left[0.001 * \hat{\gamma}_{V A R}\right]^{-1}, 2\right\}$

Step 5: $\operatorname{Draw} p(H \mid x, \theta, Q, \Psi, \Xi)$

Following Cogley and Sargent (2005) and Primiceri (2005) the VAR can be written as

$F_{t} \theta_{t}(L) x_{t}=H_{t}^{0.5} \tilde{e}_{t} \equiv \tilde{y}_{t}$ where $\tilde{e}_{t} \sim N(0, I)$. Taking logs of the squares we have

$\log \tilde{y}_{i t}^{2}=\log h_{i t}+\log \tilde{e}_{i t}^{2}$. The conditional volatility process is given by (2.3) on the body of the

paper. Estimation of $h_{i t}$ is accomplished equation by equation using values of $\log \tilde{y}_{i t}^{2}$ following Cogley and Sargent (2005) version of Jacquier et al. (1994) metropolis algorithm. We follow Primiceri (2005) to specify the prior:

$\log h_{0} \sim N\left\{\log \hat{h}_{V A R}, 10 * I\right\}$ where $h_{0}$ refers to the diagonal elements of diagonal matrix $H_{t}$. Step 6: $\operatorname{Draw} p(\Xi \mid x, \theta, Q, H, \Psi)$

The posterior variance of innovations to the log variance associated with VAR equation $i$ is based on inverse Gamma conjugate priors. Each equation's volatility is treated independently.

We assume the following prior for the $h$ process associated with the diagonal matrix $H_{t}$.

$\Xi \sim I G\{0.00005,0.5\}$. Results were largely unchanged to some ranges of change in the scaling factors of the priors, and increases in the number of iterations in the Gibbs sampler. 